\title{
ONE-DAY SEMINAR ON ISLAMIZATION OF KNOWLEDGE
}

\section{Introduction}

\section{Salisu Shehu}

IIIT (International Institute of Islamic Thought) in Nigeria, in conjunction with the Muslim Forum of Bayero University, Kano, jointly organized and conducted a one-day seminar on the Islamization of knowledge. The seminar took place on 5 Rabi' al-Awwal, 1417 (20 July 1996). It was one of a series of programs designed for faculty outreach. Therefore, academic staff in the various faculties of the university were invited and constituted the primary audience.

The primary aim of the seminar was to educate and mobilize Muslim academicians in the university toward the Islamization of Knowledge program. It has been observed that, although a number of departments in the university offer Islamically oriented courses and several papers had been presented in some departmental and even some international seminars, many academic staff still do not have a proper understanding of the idea behind the Islamization of knowledge. For this reason, all the papers presented focused on the concept of Islamization of knowledge itself.

Of the papers presented, two are included here. The first paper was the keynote address delivered by Dr. Bashir Shehu Galadanci, the coordinator of IIIT in Nigeria. Dr. Galadanci gave a precise and concise summary of the journey thus far and the issues involved in the Islamization of Knowledge program. First and foremost, he gave a brief analysis of the theoretical and conceptual framework upon which the idea of the program was built. He further analyzed the divergent views and the controversies involved in the program. He then gave a concise historical review of its undertaking, the efforts and achievements so far made on the program, and some of the problems usually encountered both locally in Nigeria and internationally. 
The second paper was presented by Professor Danjuma Abubakar Maiwada. He is a professor in the Deparment of Education, Bayero University, Kano. The title of his paper is "Islamization of Knowledge: Background and Scope." Essentially, his paper gives the philosophical foundation of the concept Islamization of knowledge by explaining the fundamental differences between the Islamic and secular conceptions of knowledge. He also discussed the historical factors that motivated the Islamization of knowledge exercise, that is, the existence of two parallel and conflicting systems of education-Qur'anic and secular-in the Muslim world (a byproduct of colonialism).

In the second section of the paper, the scope of the Islamization of knowledge is outlined and delineated. Revealed knowledge and empirical knowledge about the real-existential (i.e., knowledge acquired by man primarily with his intellect and interactions with the world) are given as the basic premise upon which the scope of the Islamization of knowledge is discerned. The paper asserts that the two categories of knowledge are and should be integrated by permeating the entire education system with the spirit of Islamic ideology. For this purpose, the paper suggests that the work plan proposed by the late Professor Ismail al-Faruqi (1982) gives the necessary detailed steps and guidelines. The work plan is abridged in the paper. 